\title{
Does closer monitoring of thyroid function post radioiodine reduce the severity of hypothyroidism when first detected?
}

\section{Thida, NR Ellis, D Wright and SR Peacey Bradford Teaching Hospitals NHS Foundation Trust}

\section{Background}

We have previously shown that the current guidelines for monitoring thyroid function post radioiodine $(\mathrm{RI})$ therapy for hyperthyroidism, may not detect hypothyroidism until it has become severe $(\mathrm{TSH}>50 \mathrm{mu} / \mathrm{l}$ or $\mathrm{FT} 4<5 \mathrm{pmol} / \mathrm{l})$ in a significant proportion of cases $(\mathrm{J}$ Endocrinol Invest 2012, 35:82-86).

Subsequent to those findings, we developed an alternative follow up strategy post RI therapy (Intense follow up). We hoped to be able to detect the onset of hypothyroidism at a less severe stage, with resultant benefits for patients in terms of avoiding symptoms of hypothyroidism post RI.

\section{Methods}

- An alternative Intense follow-up strategy was used whereby patients had TSH and FT4 levels measured at 4 week ( 1 month) intervals post $\mathrm{RI}$ for 6 months.

- Endocrine specialist nurse-led telephone clinics (months 1,2,4 and 5) and nurse-led outpatient clinics (months 3 and 6) were introduced.

- Prospective data was collected in 104 patients who received $\mathrm{Rl}$ for hyperthyroidism.

- 101 patients were followed up after a single dose of RI (mean $466 \mathrm{MBq}$ ) and 3 patients were followed up after a second dose of $\mathrm{Rl}$ (mean $550 \mathrm{MBq}$ ).

\section{Results - Timing of detection of hypothyroidism during intense follow up}

- 75 / 104 patients (72\%) developed hypothyroidism during the first 6 months of follow up post RI.

- Hypothyroidism was detected in: - $16 \%$ patients at $<4$ weeks

- $36 \%$ patients at 4 to $<8$ weeks

$-28 \%$ patients at 8 to $<12$ weeks

$-12 \%$ patients at 12 to $<16$ weeks

- 3\% patients at 16 to $<20$ weeks

- $5 \%$ patients at 20 to $<24$ weeks

\section{Results - Severity of hypothyroidism when first detected}

- At first detection of hypothyroidism, during intense follow up, 8 of 75 patients $(11 \%)$ had TSH $>50 \mathrm{mU} / \mathrm{I}$ compared to 44 of 124 patients (36\%) using our previous data during traditional follow up $(p<0.001)$ and 11 of 75 patients ( $15 \%$ ) had FT4 $<5 \mathrm{pmol} / \mathrm{l}$ compared to 34 of 124 (27\%) using our previous data during traditional follow up $(p<0.03)$ (REF: Peacey et al. J Endocrinol Invest 2012, 35:82-86)

- Comparing intense follow-up with traditional follow-up; median TSH was $11 \mathrm{mU} / \mathrm{l}$ vs $32 \mathrm{mU} / \mathrm{l}(\mathrm{p}<0.005)$ and median FT4 was $8 \mathrm{pmol} / \mathrm{l} \mathrm{vs} 7 \mathrm{pmol} / \mathrm{l}$ $(P<0.02)$ when hypothyroidism was first detected.

TSH level when hypothyroidism first detected post RI using intense follow up

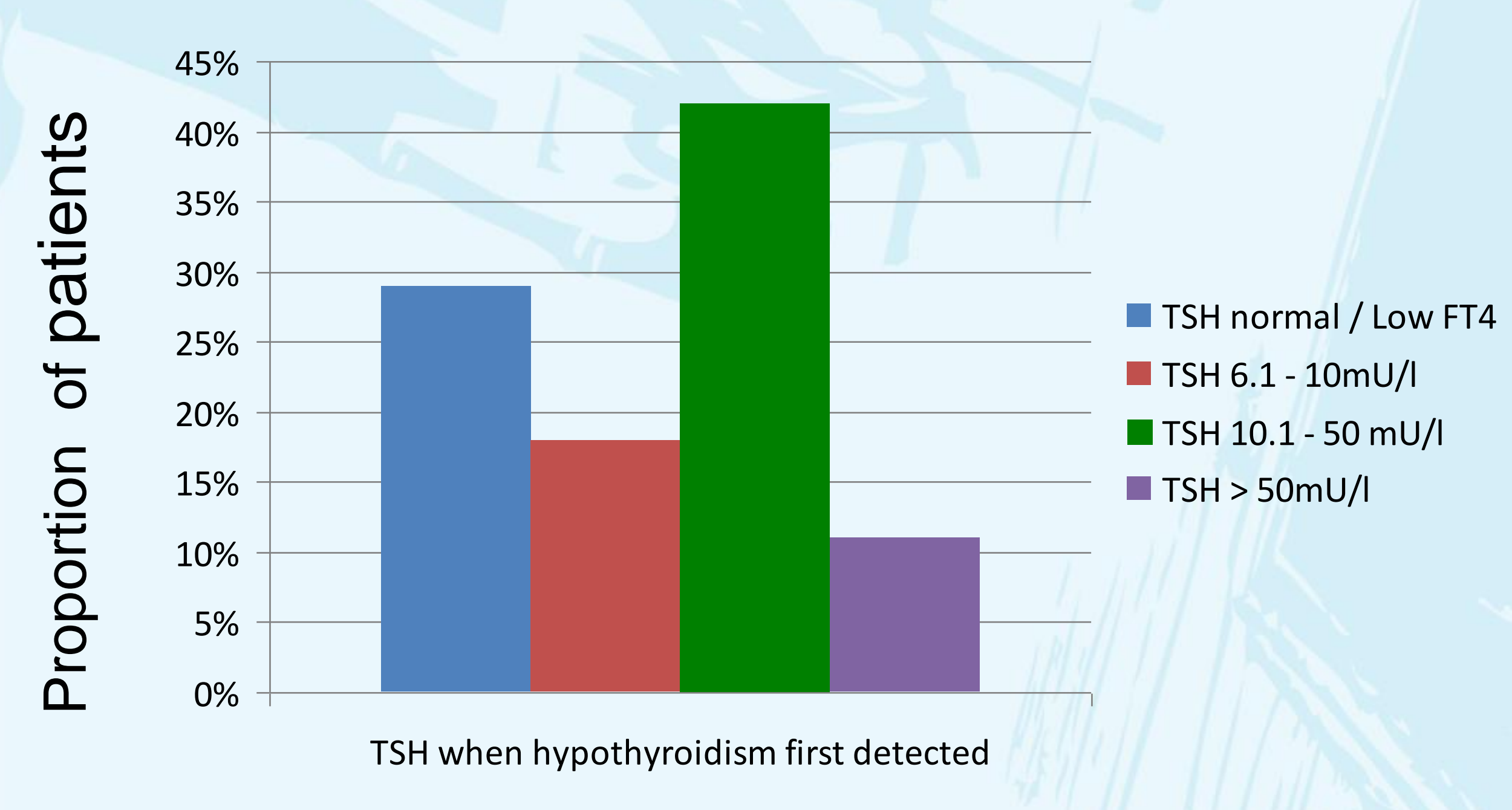

Free T4 level when hypothyroidism first detected post RI using intense follow up

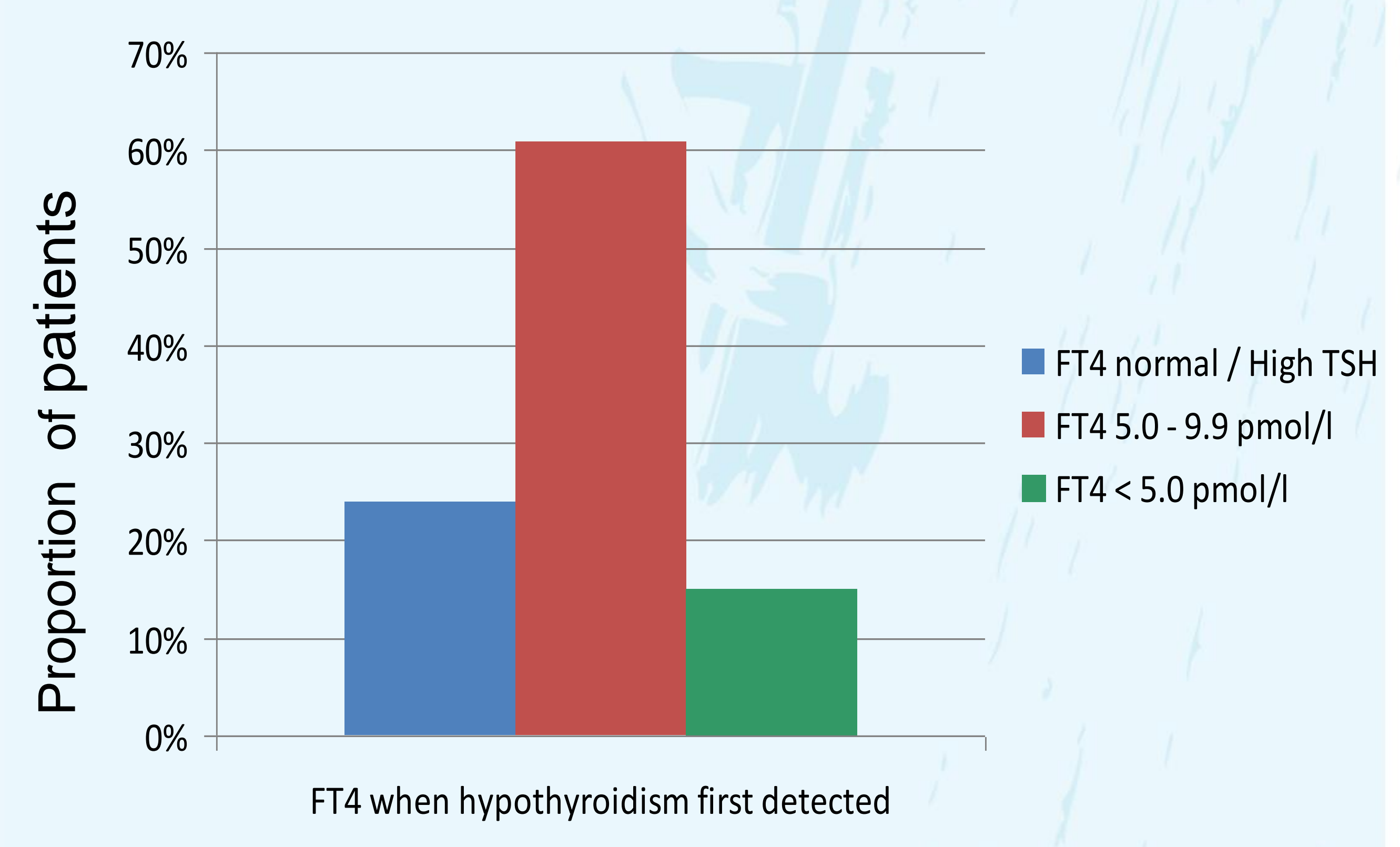

Severity of hypothyroidism at first detection: Intense and Traditional follow up

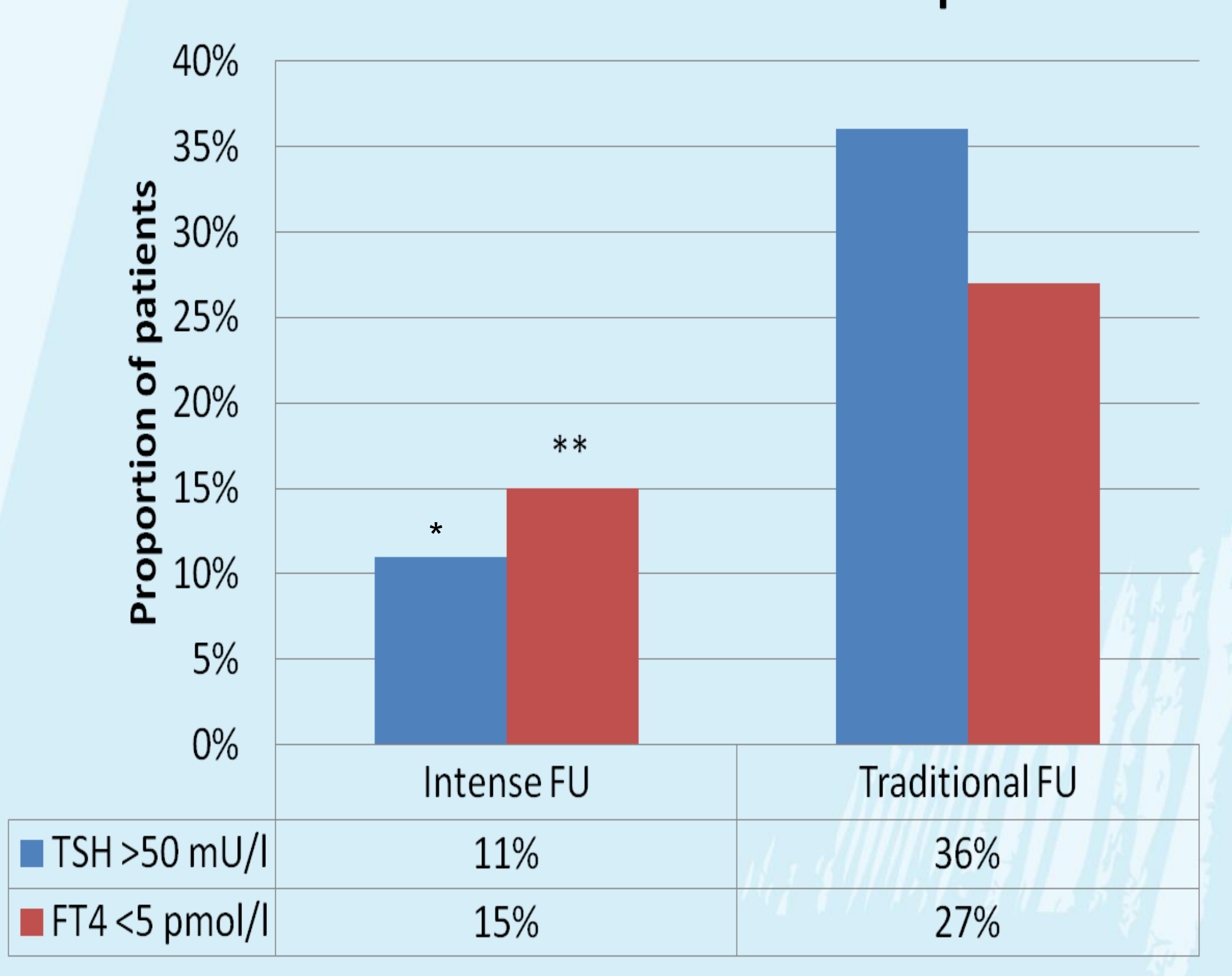

${ }^{*} p<0.001,{ }^{* *} p<0.03$; 'Traditional FU' data taken from Peacey et al, J Endocrinol Invest 2012, 35:82-86

\section{Summary}

- Intense follow up detects hypothyroidism when TSH is still normal in $29 \%$ cases

- Intense follow up detects hypothyroidism when FT4 is still normal in $24 \%$ cases

- Intense follow up with monthly biochemistry for 6 months post RI detects the onset of hypothyroidism at a less severe stage compared to traditional follow up

\section{Conclusion}

Post RI hypothyroidism is often not detected until it is relatively severe when traditional follow up is used.

Monthly biochemistry post $\mathrm{RI}$ detects the onset of hypothyroidism at a less severe stage.

A combination of nurse-led telephone and nurse-led outpatient follow up post $\mathrm{RI}$ allows more intense follow up.

Detection at an earlier stage may reduce symptoms from hypothyroidism and make RI therapy more acceptable to patients. 